\title{
Highly Sensitive Detection of Trace Tetracycline in Water Using a Metal-Organic Framework-Enabled Sensor
}

\author{
Jiezeng Chen, ${ }^{1,2}$ Hongying Shu, ${ }^{2}$ Pingping Niu, ${ }^{1,2}$ Pinghua Chen $\mathbb{D}^{1,2}$ and Hualin Jiang $\mathbb{D}^{1,2}$ \\ ${ }^{1}$ Key Laboratory of Jiangxi Province for Persistent Pollutants Control and Resources Recycle, Nanchang Hangkong University, \\ Nanchang 330063, China \\ ${ }^{2}$ Department of Applied Chemistry, College of Environmental and Chemical Engineering, Nanchang Hangkong University, \\ Nanchang 330063, China \\ Correspondence should be addressed to Pinghua Chen; cph1979@126.com and Hualin Jiang; hua20022000@126.com
}

Received 17 September 2021; Accepted 9 November 2021; Published 23 November 2021

Academic Editor: Xue Tao Guo

Copyright (c) 2021 Jiezeng Chen et al. This is an open access article distributed under the Creative Commons Attribution License, which permits unrestricted use, distribution, and reproduction in any medium, provided the original work is properly cited.

\begin{abstract}
Due to the abuse application of antibiotics in the recent decades, a high level of antibiotics has been let out and remains in our environment. Electrochemical sensing is a useful method to sensitively detect antibiotics, and the key factor for a successful electrochemical sensor is the active electrode materials. In this study, a sensitive electrochemical sensing platform based on a metal-organic framework (MOF) of MIL-53 (Fe) was facilely fabricated. It shows highly selective and sensitive detection performance for trace tetracycline. Differential pulse voltammetry (DPV) was applied to analyze the detection of tetracycline. The linear range of tetracycline detection was $0.0643 \mu \mathrm{mol} / \mathrm{L}-1.53 \mu \mathrm{mol} / \mathrm{L}$, and the limit of detection (LOD) is $0.0260 \mu \mathrm{mol} / \mathrm{L}$. Furthermore, the MOF-enabled sensor can be effectively used in actual water bodies. The results indicate that the electrochemical sensor is a high potential sensing platform for tetracycline.
\end{abstract}

\section{Introduction}

Tetracycline is a typical antibiotic which has been widely used to treat infections caused by Gram-positive and Gramnegative bacterium in both human and animals. Furthermore, it has been also used as growth promoting agents in livestock breeding industry [1]. Because of its low cost and wide-spectrum antibacterial activity, abuse application of tetracycline was common in the past decades. As a result, high tetracycline residue was detected in lots of environmental areas nowadays, including soil, water, and animal productions [2]. Long-term exposure to antibiotics can cause directed toxicity or result in allergies, also boosting the prevalence of antibiotic resistance [3-6]. Tetracycline, as one of the most applied antibiotics, is considered to be carcinogenic, and depressive to bone growth besides the common adverse effects of antibiotics [7]. Tetracycline is a typical emerging contaminant (ECs), which usually refers to those highly concerned environmental substances because of their detecting frequency and potential dangers, but the environmental management details such as monitor regulations and emission control limits are still in blank [8]. Thereafter, highly sensitive and fast responsive techniques for tetracycline detection are urgently needed, which are important for the governors to formulate the suitable management policies.

Numerous methods have been developed for tetracycline detection. Chromatographic methods are the sensitive methods to detect tetracycline, including high performance liquid chromatography (HPLC) [9], liquid chromatography coupled to mass spectrometry (LCMS) [10], and thin-layer chromatography (TLC) [11]. Nevertheless, some inherent drawbacks, such as time-costing, needing highly professional operators, and luxury devices, significantly limit their wide application. Besides chromatographic methods, some other methods such as capillary electrophoresis (CE) [12] and enzyme-linked immunosorbent assay (ELISA) [13] are also applied to detect tetracycline with good performance. But inherent disadvantages including complicated pretreatments and skilled operation requirement still exist. Therefore, more convenient, rapid, sensitive, and selective techniques are 


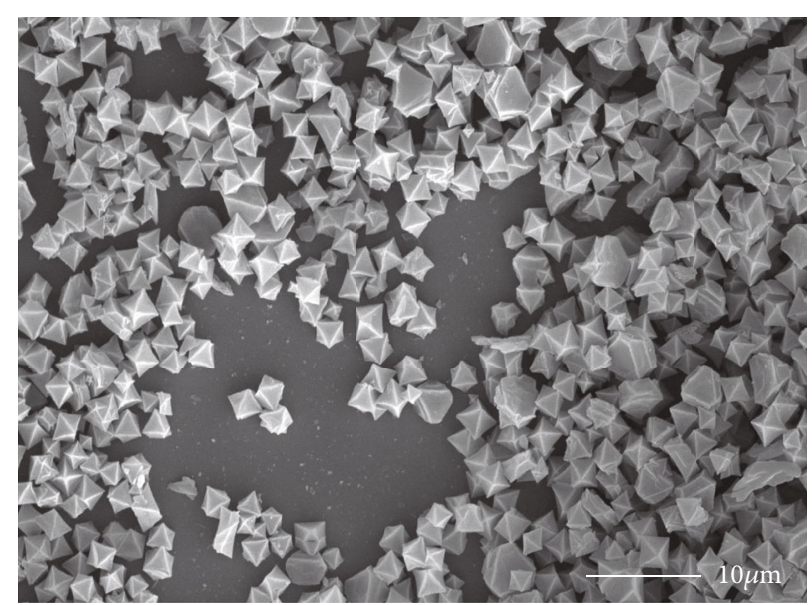

(a)

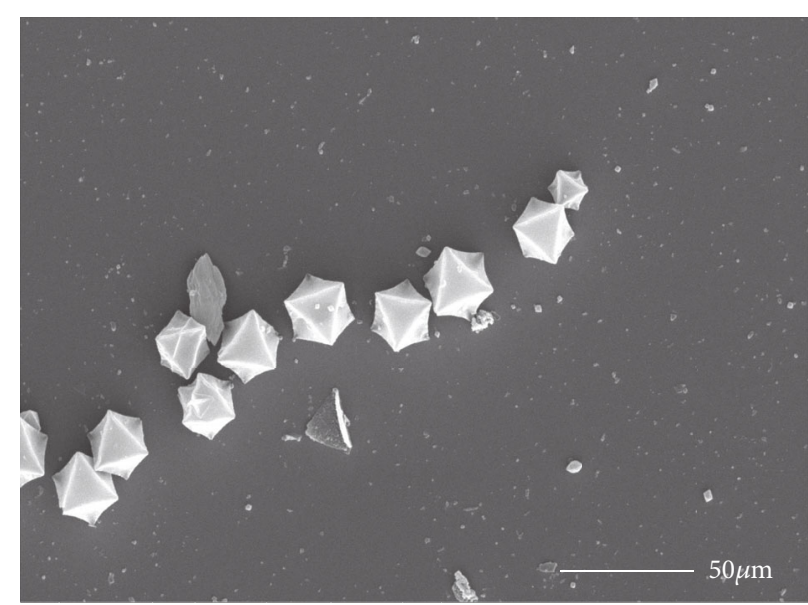

(b)

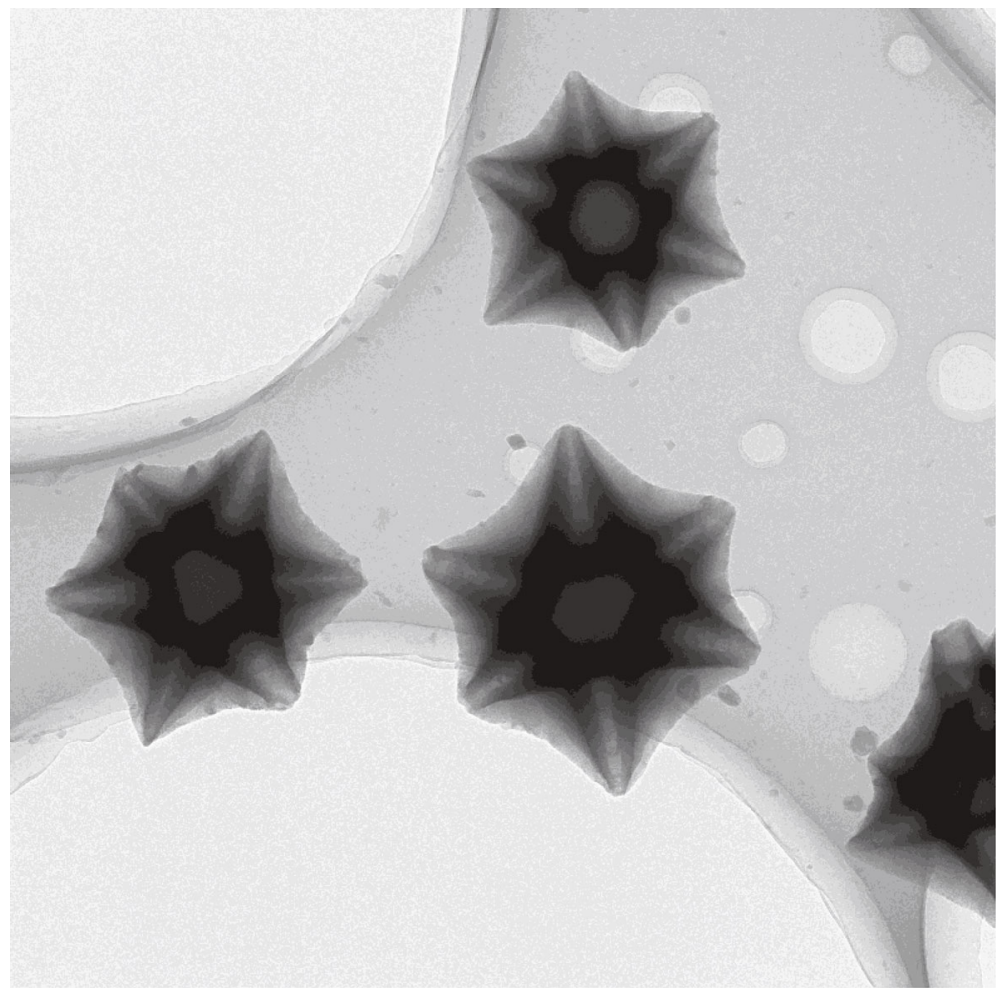

(c)

Figure 1: Continued. 


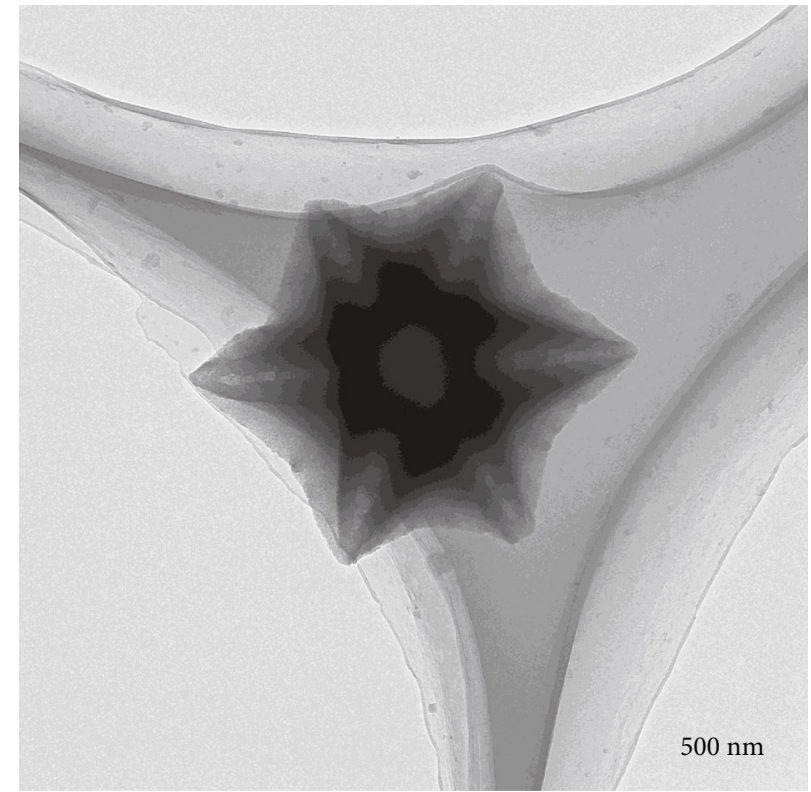

(d)

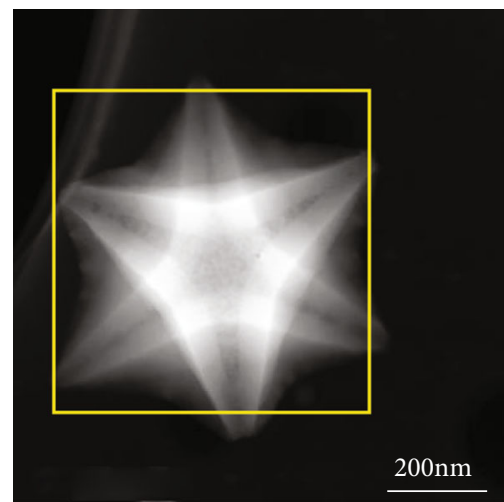

(e)

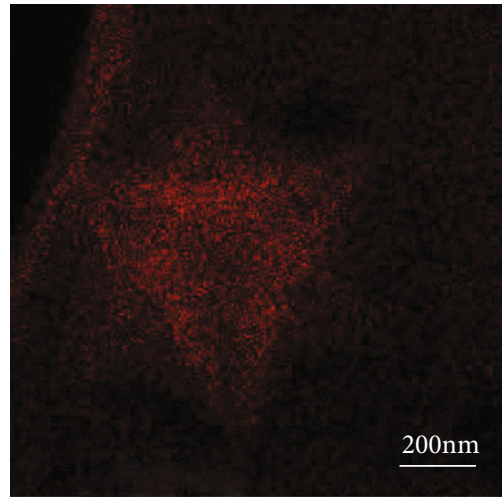

(f)

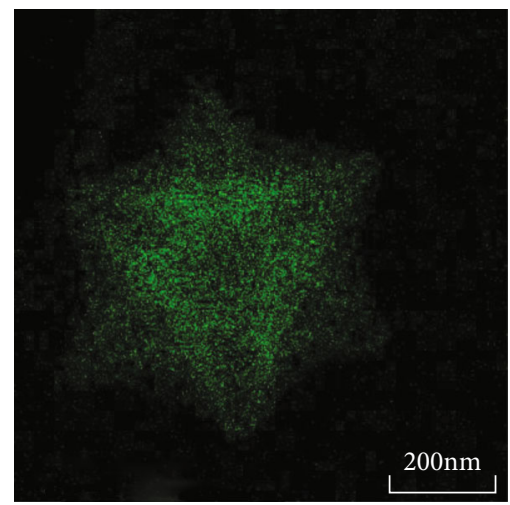

(g)

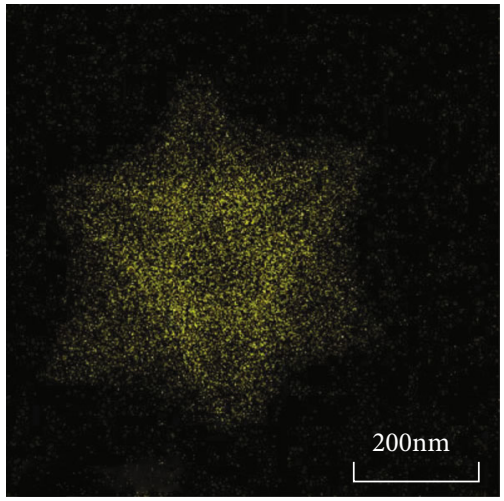

(h)

Figure 1: (a, b) SEM images of MIL-53 (Fe). (c, d) TEM images of MIL-53 (Fe). (e-h) Elemental mapping of MIL-53 (Fe).

highly required in tetracycline detection. Recently, tetracycline detection based on electrochemical sensors rapidly develops owing to their easy operation, high sensitivity, high selectivity, and real-time detection.

Metal-organic frameworks (MOFs), a polymer built by assembling metal ions and lots of organic linkers, has been widely used in catalysis [14], adsorption [15], energy storage [16], sensors [17] and so on, due to their unique advantages of plentiful micropores, large specific surface area, abundant active sites, and varied conformations [18]. Therefore, facile whereas highly performed MOF-enabled electrochemical sensors are highly demanded.

In this study, a simple electrochemical sensing platform based on a Fe containing MOF, MIL-53 (Fe), modified glass carbon electrode (denoted as MIL-53 (Fe)/GCE) was facilely fabricated. The present work demonstrates that MIL-53 $(\mathrm{Fe}) / \mathrm{GCE}$ shows highly sensitive detection performance for trace tetracycline, indicating its high potential in effective electrochemical sensor application due to the easy fabrication, high sensitivity, and low cost.

\section{Materials and Methods}

2.1. Materials. $\mathrm{N}, \mathrm{N}$-dimethylformamide (DMF), absolute ethanol $\left(\mathrm{CH}_{3} \mathrm{CH}_{2} \mathrm{OH}\right)$, and ferric chloride hexahydrate $\left(\mathrm{FeCl}_{3} \cdot 6 \mathrm{H}_{2} \mathrm{O}\right)$ were obtained from Sinopharm Chemical Reagent Co., Ltd. (Shanghai, China). p-Phthalic acid $\left(\mathrm{C}_{8} \mathrm{H}_{6} \mathrm{O}_{4}, \mathrm{H}_{2} \mathrm{BDC}\right)$ and tetracycline $\left(\mathrm{C}_{22} \mathrm{H}_{24} \mathrm{~N}_{2} \mathrm{O}_{8} \cdot \mathrm{xH}_{2} \mathrm{O}\right)$ were bought from Aladdin, China. Other chemicals were all commercial with analytical grade and used directly. Deionized water (DI water) was used through the experiments.

\subsection{Preparation of $M I L-53 \quad(\mathrm{Fe}) . \quad 0.68 \mathrm{~g} \quad(2.5 \mathrm{mmol})$} $\mathrm{FeCl}_{3} \cdot 6 \mathrm{H}_{2} \mathrm{O}$ and $0.42 \mathrm{~g}(2.5 \mathrm{mmol})$ p-phthalic acid $\left(\mathrm{H}_{2} \mathrm{BDC}\right)$ were resolved completely in $54 \mathrm{~mL}$ DMF. Then, the mixture was placed into a stainless steel autoclave with Teflon lining to react at $150^{\circ} \mathrm{C}$ for $15 \mathrm{~h}$. After that, the solid was separated and thoroughly washed. Finally, the solid was dried to obtain the MIL-53 (Fe) powder with light orange color [19]. 


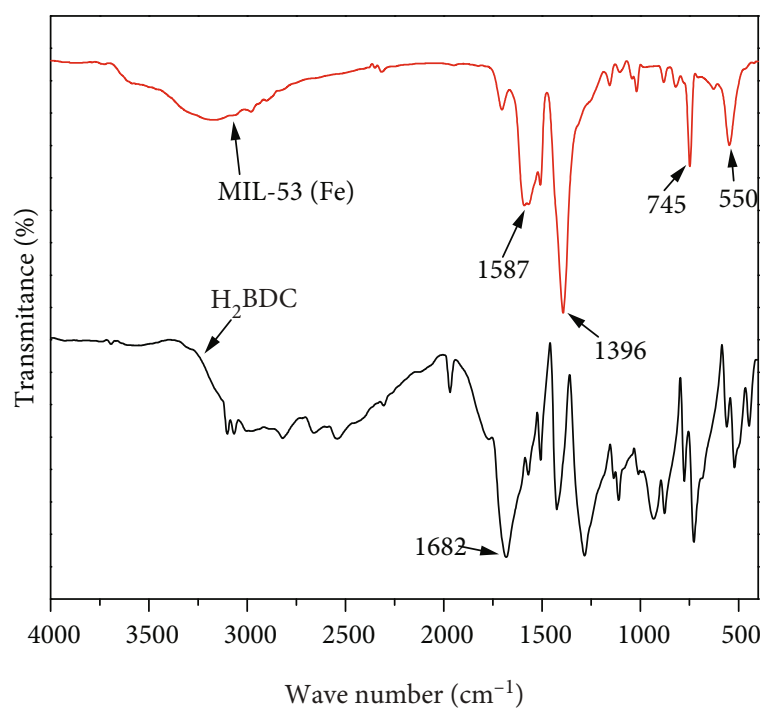

(a)

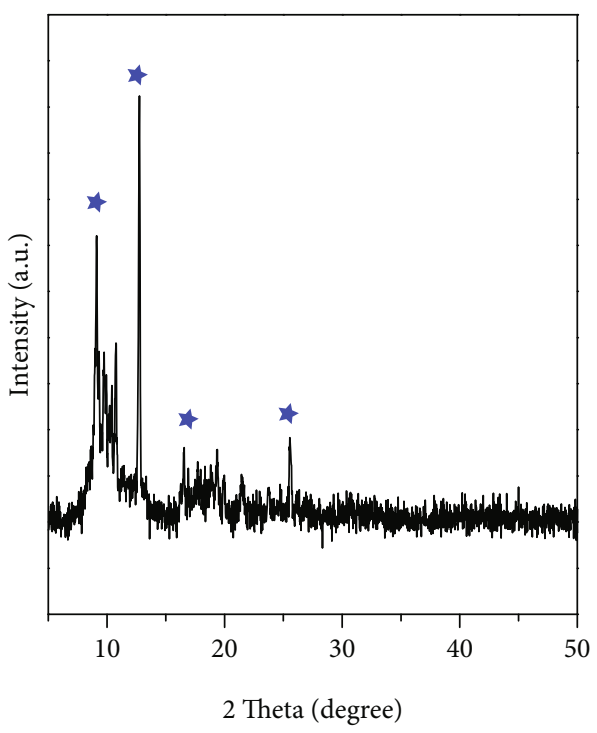

MIL-53 (Fe)

(b)

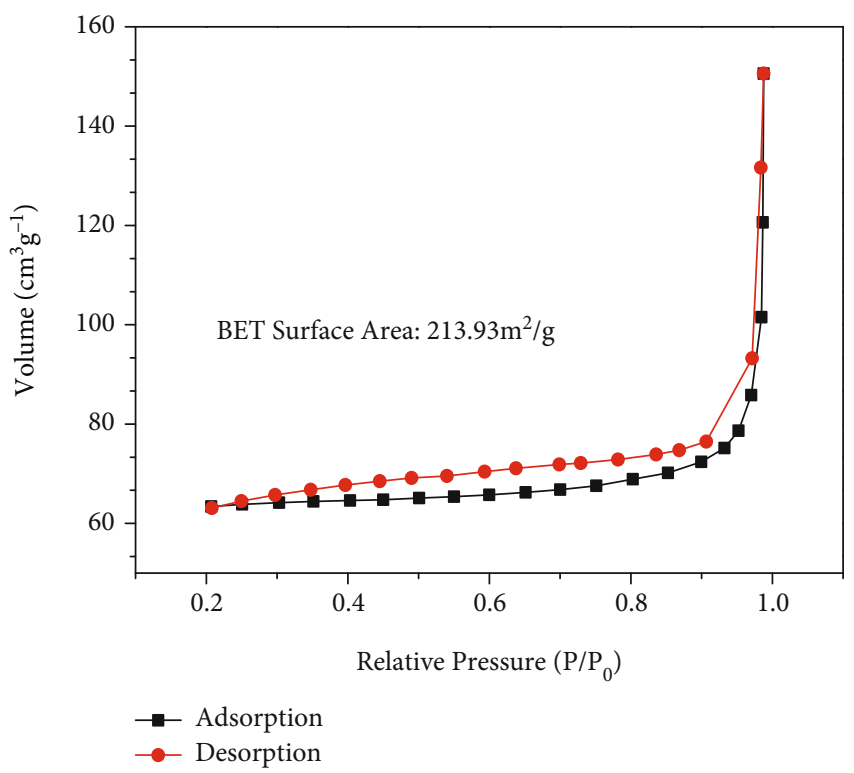

(c)

FIGURE 2: (a) FT-IR spectrum of the as-synthesized MIL-53 ( $\mathrm{Fe}$ ) and $\mathrm{H}_{2} \mathrm{BDC}$. (b) XRD spectra of MIL-53 (Fe). (c) $\mathrm{N}_{2}$ adsorption-desorption isotherms.

2.3. Preparation of MIL-53 (Fe)/GCE. 5 mg MIL-53 (Fe) was dispersed by ultrasonication in $5.0 \mathrm{~mL}$ deionized water to form a suspension $(1 \mathrm{mg} / \mathrm{mL}$ ). The GCE (diameter $3 \mathrm{~mm}$ ) was polished with alumina powder and then ultrasonically washed with dilute nitric acid ( $V_{\text {concentrated nitric acid }}: V_{\text {water }}$ $=1: 1$ ), ethanol, and DI water sequentially. At last, it was dried at room temperature (RT). $8 \mu \mathrm{L}$ suspension was dropped on the surface of the polished GCE. After it was dried, $8 \mu \mathrm{L} 0.5 \%$ Nafion was applied in drops to the surface to obtain the MIL-53 (Fe) modified GCE, denoted as MIL-53 (Fe)/GCE, and then, it was wired for electrical measurements.
2.4. Characterizations. The morphology of MIL-53 (Fe) was studied by scanning electron microscopy (SEM) (Hitachi4800, Japan) and transmission electron microscope (TEM) (JEM-2100, Japan). Samples were analyzed by X-ray powder diffractometer (XRD, Rigaku III/B max, Cu Ka). Fourier transform infrared spectroscopy (FT-IR) analyses were recorded on a Nicolet 380 (USA) instrument. BrunauerEmmett-Teller (BET, TriStar II 3020, USA) was analyzed by the $\mathrm{N}_{2}$ adsorption-desorption isotherm.

2.5. Electrochemical Experiments. All the experiments were conducted in a standard three-electrode system by an 
electrochemical workstation (CHI660E). Platinum plate electrode and $\mathrm{Ag} / \mathrm{AgCl}$ (saturated $\mathrm{KCl}$ ) were employed as a counter electrode and a reference electrode, respectively, and GCE supported by catalyst was used as a working electrode. All subsequent experiments were carried out under the condition of constant temperature at $25^{\circ} \mathrm{C}$. Before the experiment, nitrogen was used to purge the electrolyte for degassing.

Differential pulse voltammetry (DPV) and cyclic voltammetry $(\mathrm{CV})$ were tested by adding certain amount of tetracycline in $1 \mathrm{M} \mathrm{H}_{2} \mathrm{SO}_{4}$. The scanning rate of $\mathrm{CV}$ is $100 \mathrm{mV} / \mathrm{s}$, and the voltage range is $-0.7 \sim 1.2 \mathrm{~V}$. DPV was applied with voltage range of $-0.8 \sim 1.5 \mathrm{~V}$, pulse width of $50 \mathrm{~ms}$, and pulse amplitude of $50 \mathrm{mV}$.

\section{Results and Discussion}

3.1. Characterizations of MIL-53 (Fe). The SEM and TEM images of the as-prepared MIL-53 (Fe) are present in Figure 1. As one can see in SEM images (Figures 1(a) and 1(b)), the sample shows a typical octahedral structure, which was further confirmed by the TEM images (Figures 1(c) and $1(\mathrm{~d})$ ). Elemental mapping study indicates that $\mathrm{C}, \mathrm{O}$, and $\mathrm{Fe}$ all exist and uniformly distribute in the sample (Figures $1(\mathrm{e})-1(\mathrm{~h})$ ). These observations are consistent with the previous reports of MIL-53(Fe) [20, 21], suggesting the successful synthesis of MIL-53 (Fe).

MIL-53 (Fe) and the ligand p-phthalic acid $\left(\mathrm{H}_{2} \mathrm{BDC}\right)$ were investigated by FT-IR spectroscopy, and the results are indicated in Figure 2(a). One can see that MIL-53 (Fe) clearly shows distinct peaks at 1587, 1396, 745, and $550 \mathrm{~cm}^{-1}$. The strong adsorption band appearing at $1396 \mathrm{~cm}^{-1}$ is ascribed to the symmetric vibrations of the - $\mathrm{COOH}$ group, confirming the presence of carboxylate linkages in the framework of MIL-53 (Fe) [22]. The peak at $745 \mathrm{~cm}^{-1}$ is due to the bending vibration of the $\mathrm{C}-\mathrm{H}$ bond from the benzene ring $[19,23]$. Furthermore, the band at $550 \mathrm{~cm}^{-1}$ is related to the tensile trembling of the Fe-O bond [24], which indicates the formation of Fe-oxo cluster linking the metal and the carboxyl group. $\mathrm{H}_{2} \mathrm{BDC}$ shows a clear characteristic band of carboxyl group asymmetric vibrations at $1682 \mathrm{~cm}^{-1}$. It is noted that this band in MIL-53 $(\mathrm{Fe})$ shifts to $1587 \mathrm{~cm}^{-1}$, indicating the carboxyl group of $\mathrm{H}_{2} \mathrm{BDC}$ coordinated with the metal center and formed the complex of MIL-53 (Fe) [25]. The FT-IR analysis indicate that MIL-53 $(\mathrm{Fe})$ is successfully synthesized.

The structure of MIL-53 $(\mathrm{Fe})$ was studied by XRD spectra. As shown in Figure 2(b), the spectra exhibits strong adsorption bands at $9.17^{\circ}, 12.7^{\circ}, 17.6^{\circ}$, and $25.5^{\circ}$, which are consistent with the characteristic XRD spectra of MIL-53 (Fe) [21]. This result confirms the successful preparation of MIL-53(Fe).

In order to study the surface area and pore diameter of the as-synthetic MIL-53(Fe), the material were subjected to BET analysis. As shown in Figure 2(c), the $\mathrm{N}_{2}$ adsorptiondesorption isotherms shows a typical $\mathrm{H} 3$ type hysteresis ring, which indicates the existence of mesopores formed by accumulation. The BET special surface area of MIL-53 (Fe) is calculated to be $213.93 \mathrm{~m}^{2} / \mathrm{g}$. The high BET special area

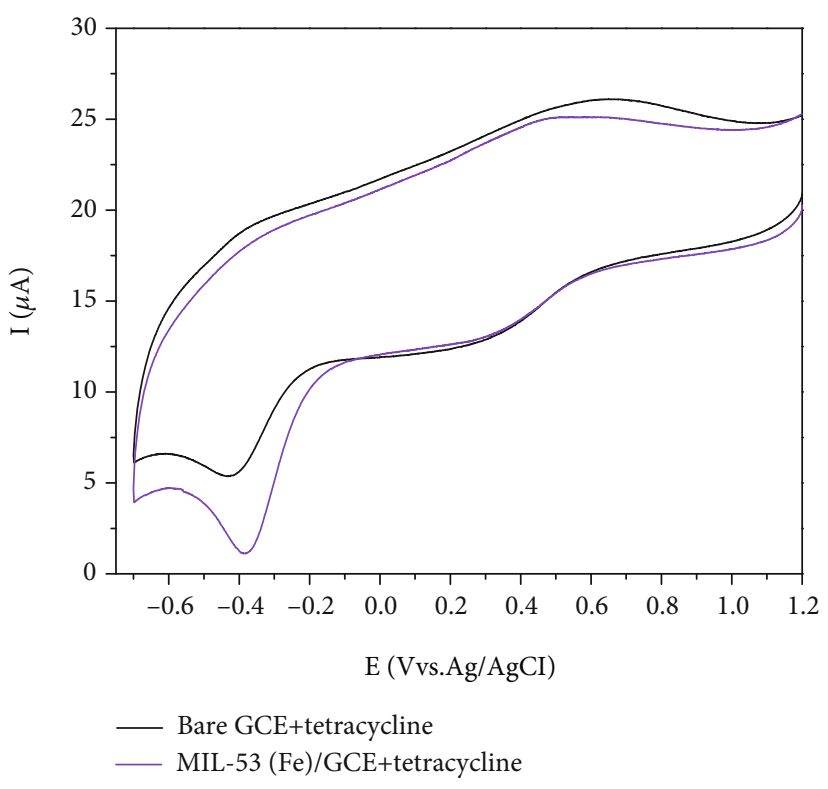

Figure 3: CVs of bare GCE and MIL-53 (Fe)/GCE in $1 \mathrm{M} \mathrm{H}_{2} \mathrm{SO}_{4}$ with $1.278 \mu \mathrm{mol} / \mathrm{L}$ tetracycline, respectively.

and mesopores can increase the molecular interaction between the analyte and the active electrode material, promoting the sensing performance [26-29].

3.2. Electrochemical Characterization of MIL-53 (Fe). The electrochemical behaviors of tetracycline over bare GCE and MIL-53 (Fe)/GCE were investigated in $1 \mathrm{M} \mathrm{H}_{2} \mathrm{SO}_{4}$ via $\mathrm{CV}$. It can be seen in Figure 3 that the reduction peak in the range of -0.35 to $-0.55 \mathrm{~V}$ is sensitive, so it is measured as a response signal to compare the difference between the samples. It can be found that the bare GCE shows a little electrochemical response to tetracycline. As GCE was modified with MIL-53 (Fe), its response to tetracycline was significantly improved, which indicates the high electrochemical activity toward tetracycline of MIL-53 (Fe).

3.3. The Effect of $p H$. The electrochemical responses of the sensor toward tetracycline in different $\mathrm{pH}$ conditions were investigated by $\mathrm{CV}$, and the $\mathrm{pH}$ was adjusted by $\mathrm{H}_{2} \mathrm{SO}_{4}$ solution. The experiment was carried out under the following conditions: constant temperature $\left(25^{\circ} \mathrm{C}\right)$, tetracycline concentration of $0.641 \mu \mathrm{mol} / \mathrm{L}, \mathrm{pH}$ range of 0 to 2.6 , voltage range of $-0.7 \mathrm{~V} \sim 1.2 \mathrm{~V}$, and scanning rate of $100 \mathrm{mV} / \mathrm{s}$. As indicated in Figure 4(a), the reduction peak potential $\left(E_{\mathrm{p}}\right)$ in the range of -0.35 to $-0.55 \mathrm{~V}$ is sensitive; therefore, it is measured as a response signal. The reduction peak potential $\left(E_{\mathrm{p}}\right)$ and the related peak current $\left(I_{\mathrm{p}}\right)$ were plotted with $\mathrm{pH}$ values of the supporting electrolyte solution. As one can see in Figure 4(b), when the $\mathrm{pH}$ value rises from 0 to 2.6, the peak potential of the cathode changes negatively and is inversely proportional to $\mathrm{pH}$, indicating that protons are directly related to electrochemical reactions [30]. The linear relationship between peak potential $(E)$ and $\mathrm{pH}$ over MIL-53 $(\mathrm{Fe}) / \mathrm{GCE}$ towards tetracycline can be expressed as follows: $E=-0.05013 \mathrm{pH}-0.3837\left(R^{2}=0.94942\right)$. It can be found that the slope of the linear relationship is close to the 


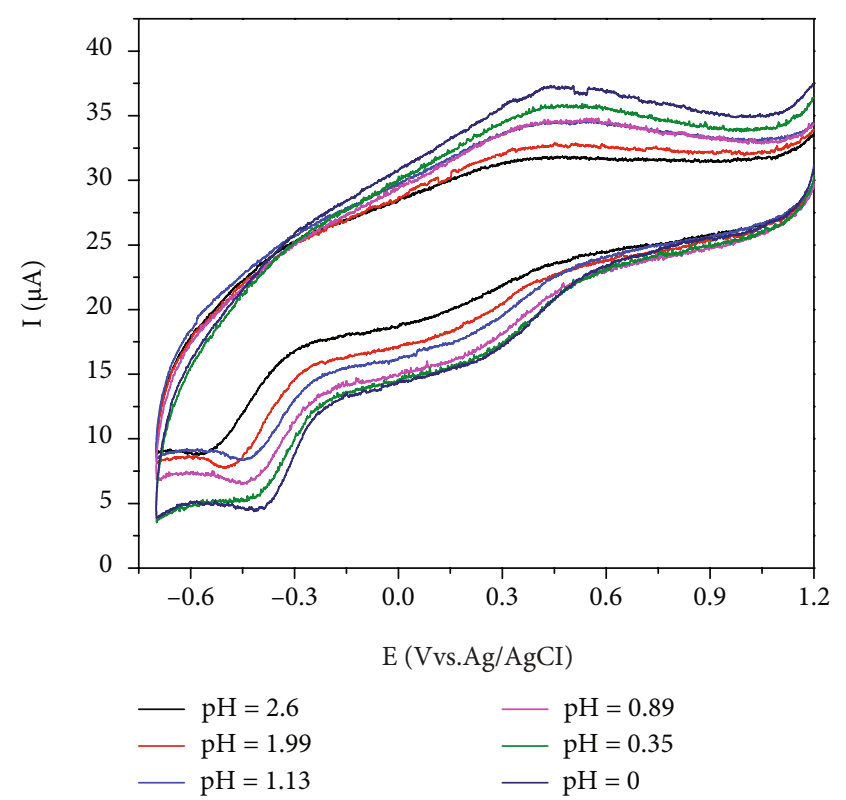

(a)

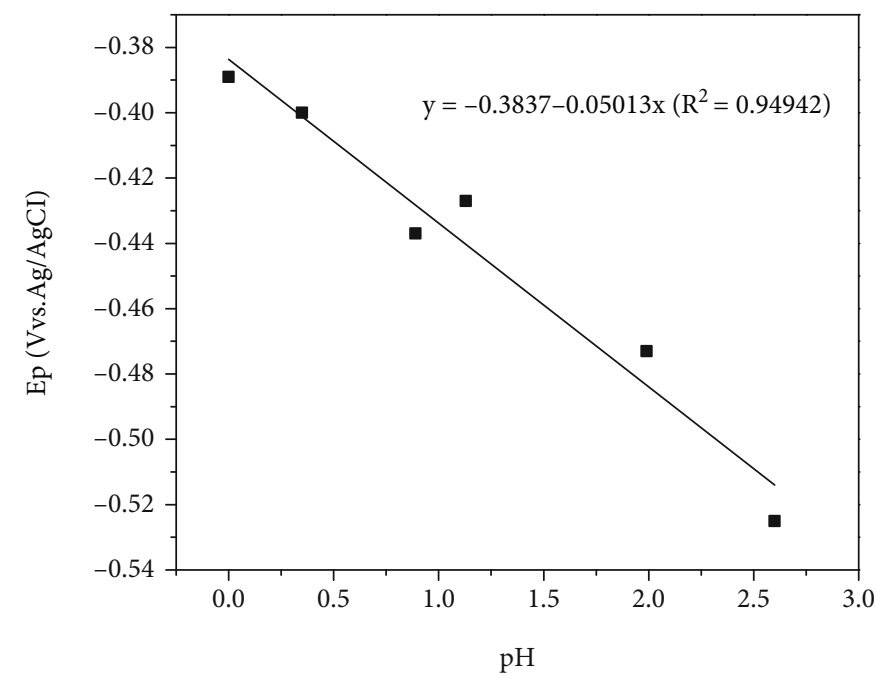

(b)

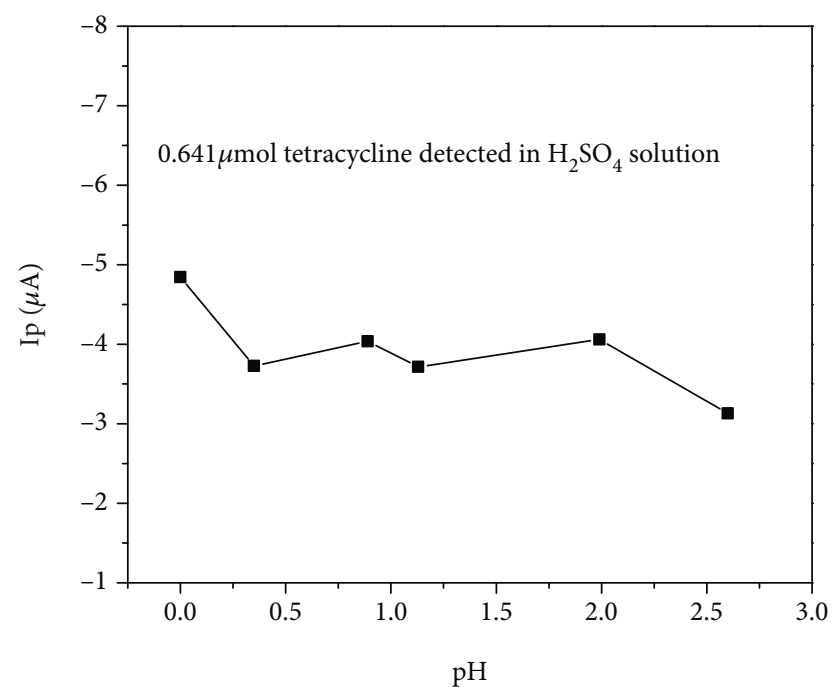

(c)

Figure 4: (a) CVs of $0.641 \mu \mathrm{M}$ tetracycline over MIL-53 (Fe)/GCE in $\mathrm{H}_{2} \mathrm{SO}_{4}$ solution with different $\mathrm{pH}$ values (0-2.6). (b) The dependence of $E_{\mathrm{p}}$ with $\mathrm{pH}$. (c) The dependence of $I_{\mathrm{p}}$ with $\mathrm{pH}$.

theoretical value of $0.059 \mathrm{~V} / \mathrm{pH}$ (according to the Nernst equation $\left.E=E_{0}-(0.059 / n) \times \mathrm{pH}\right)$ [31], indicating that the detection of tetracycline by MIL-53 (Fe) is an electrochemical reaction that the same amount of proton and electron is involved [30]. As one can see in Figure 4(c), when the $\mathrm{pH}$ value is 0 , the $I_{\mathrm{p}}$ value is the largest. When the $\mathrm{pH}$ rises from 0 to about 0.25 , the value of $I_{\mathrm{p}}$ significantly decreases. When the $\mathrm{pH}$ changes from 0.25 to 2 , the $I_{\mathrm{p}}$ changes a little but relatively stable as compared with the behaviors in other $\mathrm{pH}$ ranges, indicating $\mathrm{pH}$ does not have much effect on $I_{\mathrm{p}}$ in this range. When the $\mathrm{pH}$ is higher than 2.0 , the value of $I_{\mathrm{p}}$ dramatically decreases as the $\mathrm{pH}$ rises. This result indicates that $\mathrm{pH}=0$ can be determined as the optimum $\mathrm{pH}$ condition, because the highest $I_{\mathrm{p}}$ value is obtained.
3.4. Detecting Range and Limit of MIL-53 (Fe)/GCE. The detection of tetracycline over MIL-53 (Fe)/GCE was measured by differential pulse voltammetry (DPV) (Figure 5(a)). A certain amount of tetracycline was added in $1 \mathrm{M} \mathrm{H}_{2} \mathrm{SO}_{4}$ solution, and the DPV was carried out. The concentration of tetracycline and the related peak current $\left(I_{\mathrm{p}}\right)$ in DPV at $\sim 0.25 \mathrm{~V}\left(I_{\mathrm{p}}\right)$ are linearly related over two different continuous concentration ranges (Figure $5(\mathrm{~b})$ ). The relevant regression equation is as follows:

$0.0643 \mu \mathrm{mol} / \mathrm{L}-0.769 \mu \mathrm{mol} / \mathrm{L}$ :

$$
\operatorname{Ip}(\mu \mathrm{A})=-1.3453 * \mathrm{C}\left(\frac{\mu \mathrm{mol}}{\mathrm{L}}\right)-2.8646\left(R^{2}=9616\right)
$$




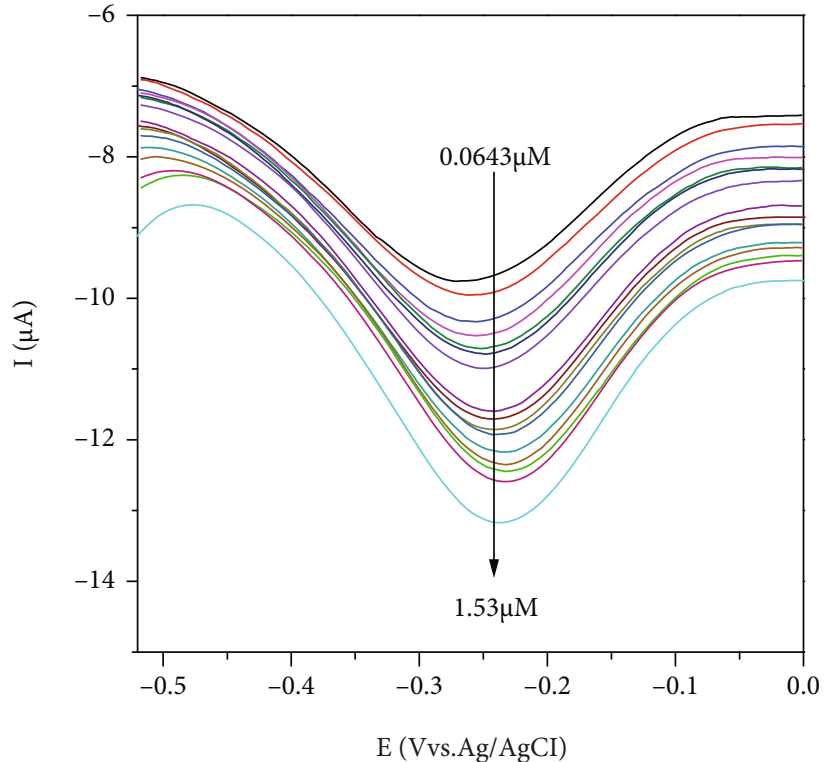

(a)

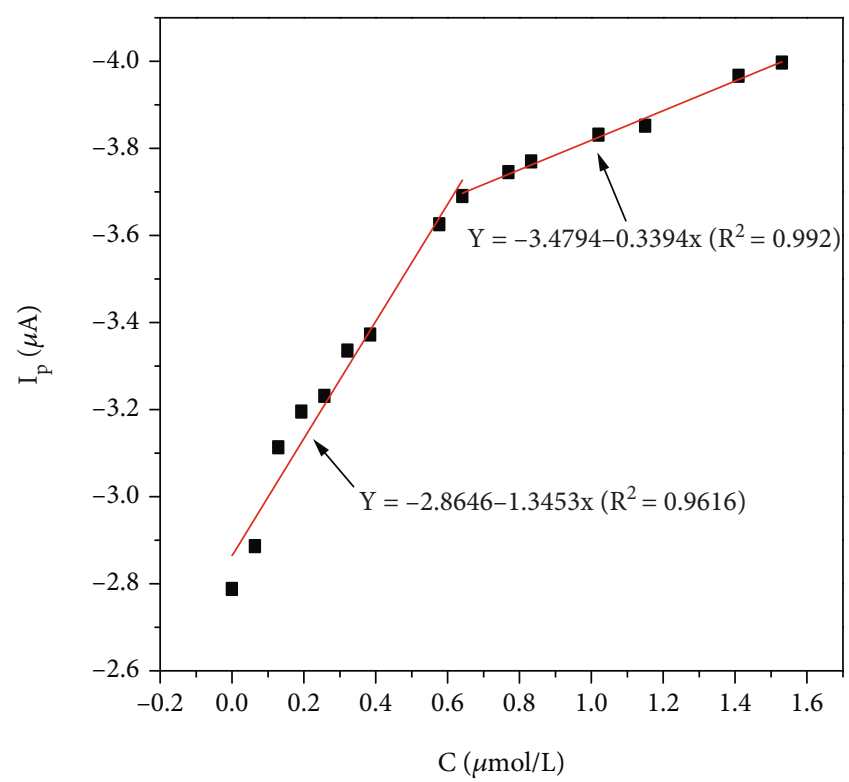

(b)

FIGURE 5: (a) DPV of tetracycline with different concentrations in $1 \mathrm{M} \mathrm{H}_{2} \mathrm{SO}_{4}$ over MIL-53 (Fe)/GCE. (b) The linear dependence of $I_{\mathrm{p}}$ with tetracycline concentration.

TABLE 1: Summary of the tetracycline detecting performance between different sensors.

\begin{tabular}{|c|c|c|c|c|c|}
\hline Sensor types & $\begin{array}{l}\text { Detection } \\
\text { techniques }\end{array}$ & $\begin{array}{l}\text { Signal transducer or active electrode } \\
\text { materials }\end{array}$ & $\begin{array}{l}\text { Linear range } \\
(\mu \mathrm{M})\end{array}$ & $\begin{array}{c}\text { Detection limit } \\
(\mu \mathrm{M})\end{array}$ & References \\
\hline \multirow{5}{*}{ Optical sensor type } & \multirow{2}{*}{ Colorimetric } & AuNPs & $0.95-29.25$ & 0.38 & {$[33]$} \\
\hline & & TMB & $0.01-1$ & 0.045 & {$[34]$} \\
\hline & \multirow{2}{*}{ Fluorescence } & MIP-APS-QDs & $0.12-0.37$ & 0.54 & {$[35]$} \\
\hline & & MIP-MAA-QDs & $0.10-0.37$ & 0.50 & {$[36]$} \\
\hline & SPR & AgNPs & $112.5-11250$ & 29.25 & {$[37]$} \\
\hline \multirow{7}{*}{$\begin{array}{l}\text { Electrochemical sensor } \\
\text { type }\end{array}$} & \multirow{3}{*}{ DPV } & $\mathrm{Fe} / \mathrm{Zn}-\mathrm{MMT} / \mathrm{GCE}$ & $0.30-52$ & 0.10 & {$[1]$} \\
\hline & & MIOPPy-AuNP/SPCE & $1-20$ & 0.65 & {$[37]$} \\
\hline & & MWCNTs/GCE & $0.01-10$ & 0.005 & {$[38]$} \\
\hline & \multirow{3}{*}{$\mathrm{CV}$} & PtNPs/C/GCE & $9.99-44.01$ & 4.28 & [39] \\
\hline & & UV-DNA/GCE & $0.3-90$ & 0.27 & {$[40]$} \\
\hline & & MIP/MWCNTs-AuNPs/GCE & $0.225-90$ & 0.09 & {$[41]$} \\
\hline & DPV & MIL-53(Fe)/GCE & $0.0643-1.53$ & 0.026 & This work \\
\hline
\end{tabular}

SPR: surface plasmon resonance; DPV: differential pulse voltammetry; CV: cyclic voltammetry; AuNPs: Au nanoparticles; TMB: 3,3',5,5' -tetramethylbenzidine; MIP-APS-QDs: molecularly imprinting polymer-3-mercapto-propyltriethoxysilane-CdTe quantum dots; MIP-MAA-QDs: molecmolecularly imprinting polymer-methacrylic acid-CdTe quantum dots; AgNPs: Ag nanoparticles; Fe/Zn-MMT/GCE: iron/zinc cation-exchanged montmorillonite catalyst on glassy carbon electrode; MIOPPy-AuNP/SPCE: screen-printed carbon electrodes modified with molecularly imprinted overoxidized polypyrrole and gold nanoparticles; MWCNTs/GCE: multiwalled carbon nanotubes, modified glass carbon electrode; PtNPs/C/GCE: platinum nanoparticles supported on carbon-coated glassy carbon electrode; UV-DNA/GCE: UV irradiated DNA film modified glassy carbon electrode; MIP/MWCNTs-AuNPs/GCE: molecularly imprinting polymer and gold nanoparticles modified multiwalled carbon nanotubes, modified glass carbon electrode.

$0.769 \mu \mathrm{mol} / \mathrm{L}-1.53 \mu \mathrm{mol} / \mathrm{L}:$

$\operatorname{Ip}(\mu \mathrm{A})=-0.3394 * \mathrm{C}\left(\frac{\mu \mathrm{mol}}{\mathrm{L}}\right)-3.4794\left(R^{2}=0.9920\right)$.
The limit of detection (LOD) is calculated according to the IUPAC criterion (based on 3 times the signal-to-noise ratio, Equation (3)) [32].

$$
\mathrm{LOD}=\frac{3 \sigma}{k}
$$




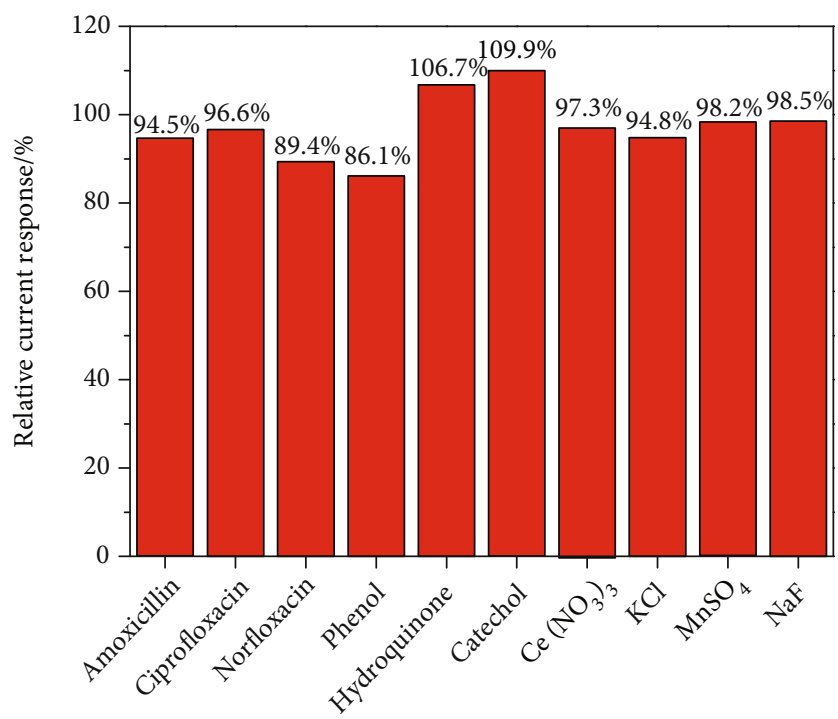

Figure 6: Amperometric response of MIL-53 (Fe)/GCE to tetracycline $(1.278 \mu \mathrm{mol} / \mathrm{L})$ coexistent with different interfering substances (other antibiotics interferences with 10 times concentration $(12.78 \mu \mathrm{mol} / \mathrm{L})$ : amoxicillin, ciprofloxacin, and norfloxacin. Typical organic interferences with 100 times concentration $(127.8 \mu \mathrm{mol} / \mathrm{L})$ : phenol, hydroquinone, and catechol. Typical inorganic interferences with 100 times concentration $(127.8 \mu \mathrm{mol} / \mathrm{L})$ : $\mathrm{Ce}^{3+}, \mathrm{NO}^{3-}, \mathrm{K}^{+}, \mathrm{Cl}^{-}, \mathrm{Mn}^{2+}, \mathrm{Na}^{+}$, and $\left.\mathrm{F}^{-}\right)$. It was pair system that one interference coexistent with tetracycline in one test, and the DPV responses of the sensor to tetracycline were recorded. Other conditions were the same as described elsewhere. The DPV response of the sensor to bare tetracycline was set as the value of $100 \%$.

where $\sigma$ is the standard deviation of a blank $(n=20)$ and $k$ is the slope of the calibration curve. Therefore, the limit of detection is estimated to be $0.0260 \mu \mathrm{mol} / \mathrm{L}$.

Because tetracycline is one of the ECs, there is no official permitted limitation of tetracycline in water at present. It is no other than comparison of detecting performance of MIL-53 (Fe)/GCE and other tetracycline sensors can be used to evaluate the detecting efficiency of MIL-53 (Fe)/GCE. For this purpose, the parameters of detection techniques, linear range, and limit of detection of MIL-53 (Fe)/GCE were compared to other reported tetracycline sensors. As one can see in Table 1, the performance of MIL-53 (Fe)/GCE is comparable with those of others, even higher in some aspects (especially the detection limit). The comparison indicate that MIL-53 (Fe)/GCE is an effective sensing platform, which can sufficiently meet the requirement of tetracycline detection application.

3.5. Selective Study. To evaluate the selectivity of the electrochemical sensor for tetracycline, the interfering substances (with significantly high concentrations than tetracycline) that may occur during the detection of tetracycline were studied. As shown in Figure 6, typical organic interferences such as phenol, hydroquinone, and catechol have a little effect on the detection of tetracycline. When inorganic ions such as $\mathrm{Ce}^{3+}, \mathrm{NO}^{3-}, \mathrm{K}^{+}, \mathrm{Cl}^{-}, \mathrm{Mn}^{2+}, \mathrm{Na}^{+}$, and $\mathrm{F}^{-}$was added, there is no significant change in the amperometric response of tetracycline. When other antibiotics (such as amoxicillin, ciprofloxacin, and norfloxacin) are present in the solution of tetracycline, there is almost no effect on the detection of tetracycline. The above results indicate that MIL-53 (Fe)/GCE has a high selectivity to detect tetracycline.

3.6. Reproducibility and Stability of Modified Electrodes. For the purpose of characterizing the repeatability of the sensor for tetracycline detection, seven different glassy carbon electrodes were applied to prepare seven different MIL-53 $(\mathrm{Fe}) / \mathrm{GCEs}$, and their tetracycline detection performance were measured. After 7 parallel measurements, the relative standard deviation (RSD) was obtained as $7.3 \%$ (Figure 7(a)), showing that the sensor has a high repeatability to detect tetracycline. For the purpose of investigating the stability of the sensor, 100 cycles of voltammetric scanning were performed. As indicated in Figure 7(b), after $100 \mathrm{CV}$ cycles, there is no significant change in the reduction peak current, showing that the sensor has a high stability. The periodic stability of the sensor was evaluated, too. 3 weeks later after MIL-53 (Fe)/GCE was placed in air at RT, the sensor was employed to measure tetracycline via DPV again (detection conditions are the same as above). The results showed that an initial $I_{\mathrm{p}}$ value of more than $96 \%$ was retained (Figure $7(\mathrm{c})$ ), showing the high period stability of the sensor.

3.7. Application in Actual Water. Natural water samples including tap water and river water were used to evaluate the practical application of MIL-53(Fe)/GCE. Tetracycline (with three concentrations of $0.321 \mu \mathrm{M}, 0.641 \mu \mathrm{M}$, and $1.278 \mu \mathrm{M}$ ) were spiked into the above actual water samples due to no tetracycline being detected in the original samples. The recovery results are shown in Table 2 . One can 


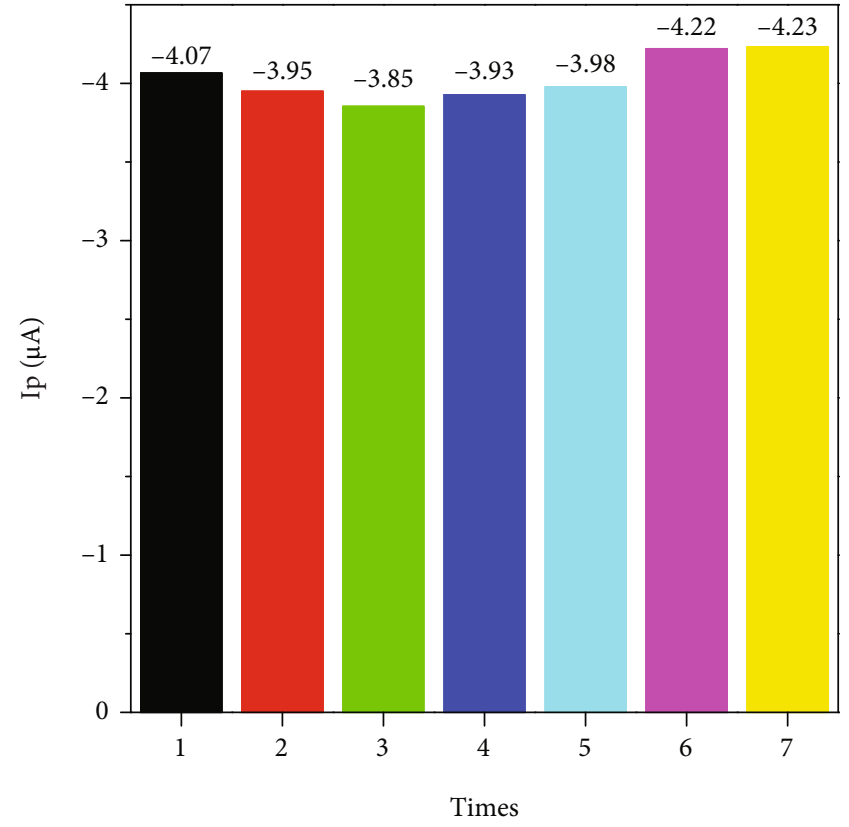

(a)

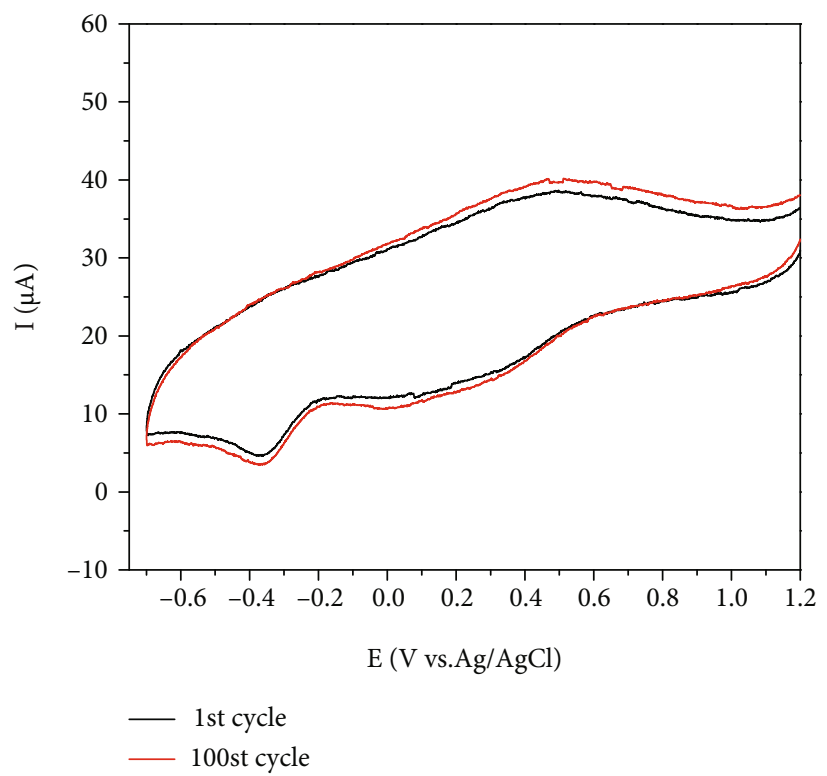

(b)

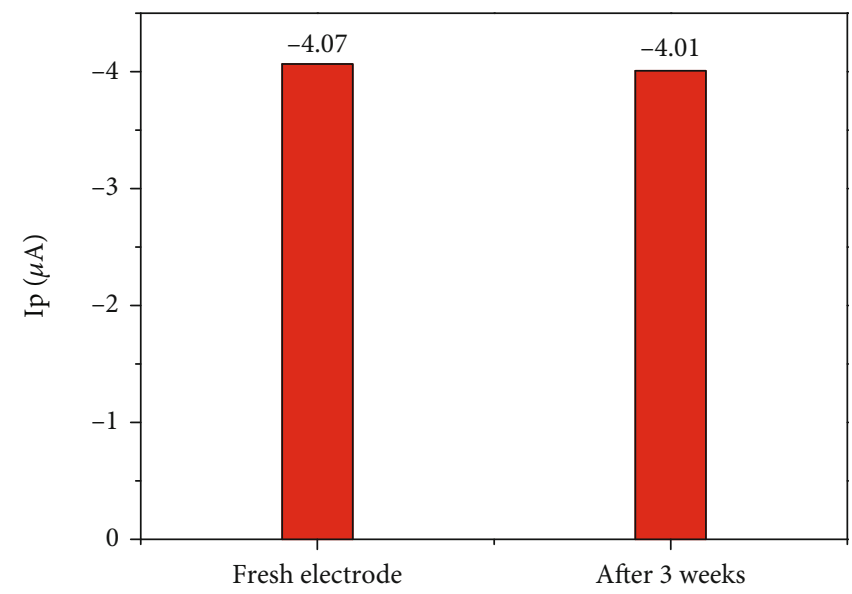

(c)

Figure 7: (a) The peak current values of DPVs of $1.278 \mu \mathrm{M}$ tetracycline in $1 \mathrm{M} \mathrm{H}_{2} \mathrm{SO}_{4}$ over 7 different MIL-53 (Fe)/GCEs. (b) The CVs of $0.641 \mu \mathrm{M}$ tetracycline in $1 \mathrm{M} \mathrm{H}_{2} \mathrm{SO}_{4}$ detected by MIL-53 (Fe)/GCE in the first and 100th cycle. (c) The $I_{\mathrm{p}}$ values of DPVs of $1.278 \mu \mathrm{M}$ tetracycline in $1 \mathrm{M} \mathrm{H}_{2} \mathrm{SO}_{4}$ over MIL-53 (Fe)/GCE and that after 3 weeks.

TABLe 2: Detection of tetracycline in tap water and river water.

\begin{tabular}{lccc}
\hline Sample & $\begin{array}{c}\text { Added tetracycline } \\
(\mathrm{M})\end{array}$ & $\begin{array}{c}\text { Found tetracycline } \\
(\mathrm{M})\end{array}$ & $\begin{array}{c}\text { Recovery } \\
(\%)\end{array}$ \\
\hline Tap water & $3.21 \times 10^{-7}$ & $3.61 \times 10^{-7}$ & 112.46 \\
Tap water & $6.41 \times 10^{-7}$ & $5.97 \times 10^{-7}$ & 93.14 \\
Tap water & $1.278 \times 10^{-6}$ & $1.06 \times 10^{-6}$ & 82.94 \\
River water & $3.21 \times 10^{-7}$ & $3.70 \times 10^{-7}$ & 115.26 \\
River water & $6.41 \times 10^{-7}$ & $6.95 \times 10^{-7}$ & 108.42 \\
River water & $1.278 \times 10^{-6}$ & $1.35 \times 10^{-6}$ & 105.63 \\
\hline
\end{tabular}

see that the sensor has relative high recovery rates in actual water.

\section{Conclusion}

An electrochemical polymer sensor of tetracycline based on MIL-53 (Fe) was successfully developed in this work. It shows high tetracycline sensing performance in concentration range of $0.0643 \mu \mathrm{mol} / \mathrm{L}-0.769 \mu \mathrm{mol} / \mathrm{L}$ and 0.769 $1.53 \mu \mathrm{mol} / \mathrm{L}$, and the LOD can reach $0.0260 \mu \mathrm{mol} / \mathrm{L}$. The sensor exhibits high reproducibility, anti-interference ability, and stability. Moreover, it can be efficiently used in actual water bodies. The polymer sensor can be facilely prepared and applied with high sensitivity. It has a high potential in practical application of trace tetracycline detection. 


\section{Data Availability}

The data used to support the findings of this study are included within the article.

\section{Conflicts of Interest}

The authors declare no conflicts of interest.

\section{Acknowledgments}

The work is supported by the National Natural Science Foundation of China (51978323, 42077162) and the Science Foundation for Young Scientists for Jiangxi Province-Key Project (2017ACB21034).

\section{References}

[1] T. Gan, Z. X. Shi, J. Y. Sun, and Y. M. Liu, "Simple and novel electrochemical sensor for the determination of tetracycline based on iron/zinc cations-exchanged montmorillonite catalyst," Talanta, vol. 121, pp. 187-193, 2014.

[2] A. Benvidi, S. Yazdanparast, M. Rezaeinasab, M. D. Tezerjani, and S. Abbasi, "Designing and fabrication of a novel sensitive electrochemical aptasensor based on poly (L-glutamic acid)/ MWCNTs modified glassy carbon electrode for determination of tetracycline," Journal of Electroanalytical Chemistry, vol. 808, pp. 311-320, 2018.

[3] D. Song, X. Jiang, Y. Li et al., "Metal-organic frameworksderived $\mathrm{MnO}_{2} / \mathrm{Mn}_{3} \mathrm{O}_{4}$ microcuboids with hierarchically ordered nanosheets and $\mathrm{Ti}_{3} \mathrm{C}_{2}$ MXene/Au NPs composites for electrochemical pesticide detection," Journal of Hazardous Materials, vol. 373, pp. 367-376, 2019.

[4] C. Fan, X. Zhang, N. Li et al., "Zn-MOFs based luminescent sensors for selective and highly sensitive detection of $\mathrm{Fe}^{3+}$ and tetracycline antibiotic," Journal of Pharmaceutical and Biomedical Analysis, vol. 188, 2020.

[5] J. Wenliang, L. Liu, X. Jin et al., "Co-inoculation effect of plantgrowth-promoting rhizobacteria and rhizobium on EDDS assisted phytoremediation of cu contaminated soils," Chemosphere, vol. 254, article 126724, 2020.

[6] C. Zhang, J. Wang, G. Liu, Z. Song, and L. Fang, "Impact of soil leachate on microbial biomass and diversity affected by plant diversity," Plant and Soil, vol. 439, pp. 505-523, 2019.

[7] C. M. Calixto, P. Cervini, and É. T. Cavalheiro, "Determination of tetracycline in environmental water samples at a graphite-polyurethane composite electrode," Journal of the Brazilian Chemical Society, vol. 23, pp. 938-943, 2012.

[8] M. Petrović, S. Gonzalez, and D. Barceló, "Analysis and removal of emerging contaminants in wastewater and drinking water," TrAC Trends in Analytical Chemistry, vol. 22, pp. 685-696, 2003.

[9] J. Li, L. Chen, X. Wang et al., "Determination of tetracyclines residues in honey by on-line solid-phase extraction highperformance liquid chromatography," Talanta, vol. 75, pp. 1245-1252, 2008.

[10] Q. Zhou, Y. Y. Zhang, N. Wang, L. H. Zhu, and H. Q. Tang, "Analysis of tetracyclines in chicken tissues and dung using LC-MS coupled with ultrasound-assisted enzymatic hydrolysis," Food Control, vol. 46, pp. 324-331, 2014.

[11] W. Naidong, S. Hua, E. Roets, and J. Hoogmartens, "Assay and purity control of tetracycline, chlortetracycline and oxytetra- cycline in animal feeds and premixes by TLC densitometry with fluorescence detection," Journal of pharmaceutical and biomedical analysis, vol. 33, pp. 85-93, 2003.

[12] P. Kowalski, "Capillary electrophoretic method for the simultaneous determination of tetracycline residues in fish samples," Journal of pharmaceutical and biomedical analysis, vol. 47, pp. 487-493, 2008.

[13] D. S. Aga, R. Goldfish, and P. Kulshrestha, "Application of ELISA in determining the fate of tetracyclines in landapplied livestock wastes," The Analyst, vol. 128, no. 6, pp. 658-662, 2003.

[14] Z. Zhang, Y. Xiao, Y. Lei, J. Tang, and X. Qiao, "Catalytic hydrolysis of $\beta$-lactam antibiotics via MOF-derived $\mathrm{MgO}$ nanoparticles embedded on nanocast silica," Science of The Total Environment, vol. 738, article 139742, 2020.

[15] M. A. Ahsan, V. Jabbari, M. T. Islam et al., "Sustainable synthesis and remarkable adsorption capacity of MOF/graphene oxide and MOF/CNT based hybrid nanocomposites for the removal of bisphenol A from water," Science of the Total Environment, vol. 673, pp. 306-317, 2019.

[16] D. P. Dubal, K. Jayaramulu, J. Sunil et al., "Metal-organic framework (MOF) derived electrodes with robust and fast lithium storage for Li-ion hybrid capacitors," Advanced Functional Materials, vol. 29, no. 19, 2019.

[17] Y. Cao, L. Wang, C. Shen, C. Wang, X. Hu, and G. Wang, “An electrochemical sensor on the hierarchically porous $\mathrm{Cu}-\mathrm{BTC}$ MOF platform for glyphosate determination," Sensors and Actuators B: Chemical, vol. 283, pp. 487-494, 2019.

[18] Y. Wan, J. Wan, Y. Ma, Y. Wang, and T. Luo, "Sustainable synthesis of modulated Fe-MOFs with enhanced catalyst performance for persulfate to degrade organic pollutants," Science of The Total Environment, vol. 701, 2020.

[19] P. Horcajada, C. Serre, G. Maurin et al., "Flexible porous metal-organic frameworks for a controlled drug delivery," Journal of the American Chemical Society, vol. 130, no. 21, pp. 6774-6780, 2008.

[20] X. Feng, H. Chen, and F. Jiang, "In-situ ethylenediamineassisted synthesis of a magnetic iron-based metal-organic framework MIL-53 (Fe) for visible light photocatalysis," Journal of Colloid and Interface Science, vol. 494, pp. 32-37, 2017.

[21] C. H. Zhang, W. Q. Hu, H. Jiang et al., "Electrochemical performance of MIL-53(Fe)@RGO as an Organic Anode Material for Li-ion Batteries," Electrochimica Acta, vol. 246, pp. 528$535,2017$.

[22] C. H. Zhang, L. H. Ai, and J. Jiang, "Graphene hybridized photoactive iron terephthalate with enhanced photocatalytic activity for the degradation of rhodamine B under visible light," Industrial and Engineering Chemistry Research, vol. 54, no. 1, pp. 153-163, 2015.

[23] A. Banerjee, R. Gokhale, S. Bhatnagar et al., "MOF derived porous carbon- $\mathrm{Fe}_{3} \mathrm{O}_{4}$ nanocomposite as a high performance, recyclable environmental superadsorbent," Journal of Materials Chemistry, vol. 22, no. 37, pp. 19694-19699, 2012.

[24] C. Gong, D. Chen, X. Jiao, and Q. L. Wang, "Continuous hollow $\alpha-\mathrm{Fe}_{2} \mathrm{O}_{3}$ and $\alpha$-Fe fibers prepared by the sol-gel method," Journal of Materials Chemistry, vol. 12, no. 6, pp. 1844-1847, 2002.

[25] R. Liang, F. Jing, L. Shen, N. Qin, and L. Wu, "MIL-53(Fe) as a highly efficient bifunctional photocatalyst for the simultaneous reduction of $\mathrm{Cr}(\mathrm{VI})$ and oxidation of dyes," Journal of Hazardous Materials, vol. 287, pp. 364-372, 2015. 
[26] M. Ghanbarian, S. Zeinali, and A. Mostafavi, "A novel MIL$53(\mathrm{Cr}-\mathrm{Fe}) / \mathrm{Ag} / \mathrm{CNT}$ nanocomposite based resistive sensor for sensing of volatile organic compounds," Sensors and Actuators B: Chemical, vol. 267, pp. 381-391, 2018.

[27] C. Wan, W. Wu, C. Wu, J. Xu, and L. Guan, “A layered porous $\mathrm{ZrO}_{2} / \mathrm{RGO}$ composite as sulfur host for lithium-sulfur batteries," RSC Advances, vol. 5, no. 7, pp. 5102-5106, 2015.

[28] X. Liang, X. Chen, Z. Xiang et al., "Design and synthesis of surface-controlled $\mathrm{CuO}_{\mathrm{x}} / \mathrm{rGO}$ nanocomposites with unusually high efficiency in catalytic conversion of organic reactants in the presence of $\mathrm{NaBH}_{4}$," Applied Surface Science, vol. 459, pp. 716-722, 2018.

[29] S. Navazani, A. Shokuhfar, M. Hassanisadi, A. di Carlo, N. Yaghoobi Nia, and A. Agresti, "A PdPt decorated $\mathrm{SnO}_{2}$ rGO nanohybrid for high- performance resistive sensing of methane," Journal of the Taiwan Institute of Chemical Engineers, vol. 95, pp. 438-451, 2019.

[30] A. E. Vilian, S. R. Choe, K. Giribabu et al., "Pd nanospheres decorated reduced graphene oxide with multi-functions: highly efficient catalytic reduction and ultrasensitive sensing of hazardous 4-nitrophenol pollutant," Journal of Hazardous Materials, vol. 333, pp. 54-62, 2017.

[31] J. Zhang, Q. Mei, Y. Ding, K. Guo, X. Yang, and J. Zhao, "Ordered mesoporous $\mathrm{NiCo}_{2} \mathrm{O}_{4}$ nanospheres as a novel electrocatalyst platform for 1-Naphthol and 2-Naphthol individual sensing application," ACS applied materials \& interfaces, vol. 9, pp. 29771-29781, 2017.

[32] C. Li, X. Zhang, S. Wen et al., "Interface engineering of zeolite imidazolate framework-8 on two-dimensional $\mathrm{Al}-$ metal -organic framework nanoplates enhancing performance for simultaneous capture and sensing tetracyclines," Journal of Hazardous Materials, vol. 395, 2020.

[33] L. Shen, J. Chen, N. Li, P. L. He, and Z. Li, "Rapid colorimetric sensing of tetracycline antibiotics with in situ growth of gold nanoparticles," Analytica Chimica Acta, vol. 839, pp. 83-90, 2014.

[34] Y. L. Wang, Y. J. Sun, H. C. Dai et al., “A colorimetric biosensor using $\mathrm{Fe}_{3} \mathrm{O}_{4}$ nanoparticles for highly sensitive and selective detection of tetracyclines," Sensors and Actuators B: Chemical, vol. 236, pp. 621-626, 2016.

[35] M. R. Chao, C. W. Hu, and J. L. Chen, "Comparative syntheses of tetracycline-imprinted polymeric silicate and acrylate on CdTe quantum dots as fluorescent sensors," Biosensors \& Bioelectronics, vol. 61, pp. 471-477, 2014.

[36] M. Amjadi, J. L. Manzoori, and F. Pakpoor, "Photometric determination of tetracycline based on surface plasmon resonance of silver nanoparticles," Journal of Analytical Chemistry, vol. 71, no. 3, pp. 253-258, 2016.

[37] L. Devkota, L. T. Nguyen, T. T. Vu, and B. Piro, "Electrochemical determination of tetracycline using AuNP-coated molecularly imprinted overoxidized polypyrrole sensing interface," Electrochimica Acta, vol. 270, pp. 535-542, 2018.

[38] L. Zhou, D. J. Li, L. Gai, J. P. Wang, and Y. B. Li, "Electrochemical aptasensor for the detection of tetracycline with multiwalled carbon nanotubes amplification," Sensors and Actuators B: Chemical, vol. 162, no. 1, pp. 201-208, 2012.

[39] R. T. Kushikawa, M. R. Silva, A. C. Angelo, and M. F. S. Teixeira, "Construction of an electrochemical sensing platform based on platinum nanoparticles supported on carbon for tetracycline determination," Sensors and Actuators B: Chemical, vol. 228, pp. 207-213, 2016.
[40] M. B. Gholivand and H. Khani, "Determination of tetracycline at a UV-irradiated DNA film modified glassy carbon electrode," Electroanalysis, vol. 25, no. 2, pp. 461-467, 2013.

[41] H. T. Wang, H. M. Zhao, X. Quan, and S. Chen, "Electrochemical determination of tetracycline using molecularly imprinted polymer modified carbon nanotube-gold nanoparticles electrode," Electroanalysis, vol. 23, no. 8, pp. 1863-1869, 2011. 